\title{
A EDUCAÇÃO SUPERIOR PARA INDÍGENAS NO DISCURSO DA CORTE CONSTITUCIONAL BRASILEIRA: UMA ANÁLISE DO ACÓRDÃO DA ADPF N. 186 DO SUPREMO TRIBUNAL FEDERAL
}

LA EDUCACIÓN SUPERIOR PARA LAS POBLACIONES INDÍGENAS EN EL DISCURSO DE LA CORTE CONSTITUCIONAL DE BRASIL: UN ANÁLISIS DEL PRONUNCIAMIENTO DE LA ADPF N. 186 DE LA CORTE SUPREMA

\author{
THE HIGHER EDUCATION FOR INDIGENOUS PEOPLE IN THE BRAZILIAN \\ CONSTITUTIONAL COURT DISCOURSE: AN ANALYSIS OF THE JUDGMENT ADPF N. \\ 186 OF THE SUPREME COURT
}

\author{
Eduardo Harder $^{1}$ - Ana Elisa de Castro Freitas ${ }^{2}$
}

Fecha de recepción: 24-06-2016

Fecha de aceptación y versión final: 30-08-2016

\begin{abstract}
Resumo: Em 2012 o Supremo Tribunal Federal (STF) se pronunciou acerca de uma ação judicial denominada Arguição de Descumprimento de Preceito Fundamental (ADPF) n. 186 emitindo sua posição sobre as políticas de ação afirmativa em curso nas universidades brasileiras a mais de dez anos. A decisão, um extenso Acórdão entremeado com concepções jurídicas e filosóficas, discorre sobre políticas públicas de educação superior que visam promover os ideais de igualdade e liberdade desde uma perspectiva substancial ou conforme condicionantes materiais presentes no cotidiano da sociedade brasileira. O olhar dos julgadores estava voltado, de forma preponderante, à ausência de estudantes negros nas universidades e instituições federais de ensino superior. Outra ausência examinada é a de estudantes indígenas. O tema emerge nos debates que antecedem a decisão final da corte constitucional e no próprio julgamento, os quais resultam posteriormente na Lei Federal n. 12.711/2012 (Lei de Cotas). O Acórdão de uma instância judicial superior possui a prerrogativa de servir como uma espécie de modelo a orientar as ações do Estado brasileiro.

A partir de um eixo de análise estabelecido em torno das categorias "etnia" e "raça", o presente estudo de antropologia jurídica busca examinar a configuração da presença ameríndia no repertório da corte constitucional brasileira, bem como trazer uma síntese dos fundamentos destes conceitos.
\end{abstract}

Palavras-chave: Educação Superior Indígena; Cortes Constitucionais; Ações Afirmativas; Equidade; Antropologia Jurídica; Democracias Constitucionais.

Resumen: En 2012 el Tribunal Supremo (STF) resolvió una demanda llamada Arguição de Descumprimento de Preceito Fundamental (ADPF) n. 186 y pronunció su posición sobre las políticas de acción afirmativa que se vienen implementando en las universidades brasileñas hace más de diez años. La decisión, un extenso pronunciamiento entremezclado con conceptos legales y filosóficos, analiza las políticas públicas para la educación superior para promover los ideales de igualdad y la libertad desde una perspectiva basada en las condiciones materiales presentes en la vida cotidiana de la sociedad brasileña. La mirada de los jueces se enfrentaba, preponderantemente, a la falta de estudiantes negros en las universidades y en las instituciones federales de enseñanza superior. Otra ausencia se examina en

\footnotetext{
${ }^{1}$ Advogado, mestre e doutor em Direito e docente na Universidade Federal do Paraná. Sua atuação acadêmica inclui o acompanhamento das políticas públicas voltadas aos estudantes indígenas nas universidades e os processos de reconhecimento de alteridades culturais. Correio eletrônico: eduardoharder@ufpr.br

${ }^{2}$ Bióloga, mestre em Ecologia e doutora em Antropologia Social pela Universidade Federal do Rio Grande do Sul. É docente na Universidade Federal do Paraná onde coordena o Núcleo Universitário de Educação Indígena. Suas pesquisas abrangem os campos da etnologia ameríndia, territorialidades, arte e ecologia. Correio eletrônico: anaelisa@ufpr.br
} 
relación a los estudiantes indígenas. El tema surge en los debates previos a la decisión final del tribunal constitucional y el juicio mismo, que posteriormente da lugar a la Ley Federal n. 12.711/2012. La sentencia de una instancia de la corte superior tiene la prerrogativa de servir como una especie de modelo para guiar las acciones del Estado brasileño.

A partir de un eje de análisis en torno a la categoría "etnia" y "raza", este estudio de la antropología jurídica tiene por objeto examinar la configuración de la presencia amerindia en el repertorio de la corte constitucional de Brasil y discutir los fundamentos de estos conceptos.

Palabras clave: Educación Superior de Indígenas; Tribunales Constitucionales; Acción Afirmativa; Equidad; Antropología Jurídica; Democracias Constitucionales.

\begin{abstract}
In 2012 the Supreme Court of Brazil (STF) pronounced on a lawsuit called Arguição de Descumprimento de Preceito Fundamental (ADPF) n. 186 and expressed its position on affirmative action policies implemented in brazilian universities for over ten years. The decision, an extensive judgment intermingled with legal and philosophical concepts, discusses public policy for higher education to promote the ideals of equality from a substantial perspective or as material conditions present in the daily life of brazilian society. The look of the judges was facing, preponderantly, the lack of black students in universities and federal institutions of higher education. Another absence is examined to indigenous students. The theme emerges in the discussions leading up to the final decision of the Constitutional Court and the Federal Law n. 12.711/2012. The judgment of a superior court instance has the prerogative to serve as a kind of model to guide the actions of the Brazilian State.

From an analysis axis set around the categories "ethnicity" and "race", this study of legal anthropology seeks to examine the configuration of the indigenous presence in the repertoire of brazilian Constitutional Court and bring an overview of the fundamentals of these concepts.
\end{abstract}

Key words: Indigenous Higher Education; Constitutional Courts; Affirmative Action; Equity; Legal Anthropology; Constitutional Democracies.

\title{
Constitucionalismo e Bem Viver na América Latina
}

Nas últimas décadas a democracia constitucional passou a ocupar um lugar central na vida social da América Latina, resultante direta de um cotidiano de transformações institucionais em todos os países, com escalas e temporalidades diferenciadas. Temáticas que envolvem a determinação do significado dos direitos individuais e coletivos previstos nos ordenamentos jurídicos privilegiaram a arena em que se trava a disputa pela definição de políticas públicas das esferas governamentais com paulatino deslocamento também para o poder judiciário.

O processo de judicialização das sociedades latino-americanas contemporâneas trouxe a expectativa de avanços e de justiça a segmentos sociais historicamente deslocados do centro de poder político parlamentar. As diferentes minorias étnicas ou identitárias (desde uma perspectiva do direito internacional público) ou alteridades presentes nos diferentes cenários nacionais passaram a disputar com classes e segmentos econômicos hegemônicos a definição do moderno vocabulário político contemporâneo.

O rol dos direitos fundamentais, inicialmente previstos de forma abstrata nos textos constitucionais, permitiu uma nova gramática política (Santos, 2008). Identidades coletivas passam a reivindicar o reconhecimento de sua qualidade de sujeitos de direitos que transbordam o antigo repertório individual do catálogo jurídico.

Um dos casos mais emblemáticos reside nas populações originárias das Américas, os povos indígenas. Impactados pelo processo colonial e pelas arbitrariedades cometidas por regimes militares em governos ditatoriais e guerras civis locais entre milícias e forças armadas, passaram a uma condição de protagonistas na luta por reconhecimento e alargamento da esfera da cidadania ativa. 
Cortes constitucionais de diferentes países latino-americanos passam, de um lado, a sinalizar o reconhecimento dos limites do monismo jurídico estatal e, por outro, valorizar as esferas de justiça consuetudinárias exercidas por diferentes etnias indígenas e seus mecanismos de aplicação da justiça. Essa desconcentração e descentralização do poder jurisdicional estatal, mesmo que temporariamente em alguns casos, esteve permeada pelos processos de reformas políticas e constitucionais ocorridas nas últimas décadas (Yrigoyen, 2010).

Além disso, países como o Equador e a Bolívia avançam em suas recentes reformas constitucionais reconhecendo o direito à diferença que passa, então, a compor o quadro da plurinacionalidade étnica e cultural, além dos direitos coletivos de proclamação dos denominados "direitos da natureza" (Pacha Mama), como constituintes dos demais direitos instauradores de uma cosmovisão que pretende reconstruir as possibilidades de paz socioambiental em direção ao paradigma do Bem Viver (Zaffaroni, 2013). Este plano de reconhecimento permite a incorporação de uma perspectiva territorial aberta ao pensamento ecológico que organiza as territorialidades ameríndias.

Em paralelo a este movimento, a Corte de Direitos Humanos da Organização dos Estados Americanos (OEA), com sede em São José da Costa Rica, passa de forma recorrente a emitir julgados com recomendações a seus países membros de cumprimento às normativas regionais que prescrevem o respeito aos processos locais de desenvolvimento, sem violações aos direitos culturais e territoriais dos povos indígenas. Reafirma-se, nesta instância, o princípio do Bem Viver.

$\mathrm{Na}$ escala global, a Convenção n. 169/1989 da Organização Internacional do Trabalho (OIT) reflete um lugar social diferenciado que passa a ser crescentemente ocupado pelos povos indígenas nas instâncias internacionais. A este processo somam-se os debates sobre os denominados direitos sobre a biodiversidade $\mathrm{e}$ conhecimentos tradicionais.

Em 2007, a 107 Sessão Plenária da Assembléia Geral das Nações Unidas aprovou a Declaração sobre os Direitos dos Povos Indígenas (n. 61/295), a qual mesmo sem a força dos pactos e convenções internacionais, constitui uma forte diretriz aos Estados membros da ONU.

Embora todos os países latino-americanos possuam componentes populacionais indígenas de considerável expressão, o conjunto destes pactos, recomendações e convenções assumirá características diversas em cada um deles. O tratamento jurídico conferido aos segmentos sociais indígenas nestes países não segue um mesmo padrão. São verificáveis diferenças históricas entre os processos coloniais conformadores de uma América portuguesa e das experiências coloniais espanholas.

O caso do Brasil remonta a uma longa trajetória entre uma juridicidade antiescravista e que prevê legalmente o reconhecimento territorial indígena, mas que contrasta com práticas e rotinas em suas estruturas administrativas que não correspondem a esta ideologia. Manuela Carneiro da Cunha (1987), por exemplo, descreve todo o processo de pressão de "descida aos aldeamentos indígenas" como forma de restrição da reprodução da vida social ameríndia.

O paralelo perceptível na noção de "vazios demográficos" colaborou com o processo de desterritorialização e um clima de oposição entre os interesses da sociedade nacional emergente e os dos povos originários. O ápice deste processo, 
sob o ponto de vista do reconhecimento da personalidade jurídica individual e coletiva, pode ser representado na noção presente no código civil vigente entre 1917 e 2002, no qual o indígena ou silvícola figurou como pessoa relativamente incapaz, e, portanto, sujeito à tutela do Estado a partir dos órgãos indigenistas.

A virada paradigmática representada pela Constituição Federal de 1988, desde uma intensa participação direta dos povos indígenas nos trabalhos da Assembléia Nacional Constituinte, possibilitou o fim do regime de tutela civil no Brasil, no plano formal. A participação indígena nos trabalhos constituintes apontou para vetores principais que deveriam orientar o Brasil na direção do reconhecimento dos direitos indígenas, com destaque aos eixos saúde, educação, terra e cultura (Augusto Opẽ da Silva, líder Kaingang, in: Freitas, 2014).

Não necessariamente tal reconhecimento significou de imediato a transformação no posicionamento de instituições e agentes públicos, bem como a superação do imaginário social sobre a categoria de índio genérico e folclorizado.

O lento processo de reconhecimento da pluralidade étnica e cultural no Brasil tem se revelado uma tarefa que vem sendo obstaculizada por um modelo de desenvolvimento nacional calcado no processo de exportação de produtos primários e de alargamento das fronteiras agrícolas e de exploração de minérios, incidindo diretamente sobre os territórios indígenas.

O processo de desconstrução ontológica e epistemológica das pessoas e coletividades indígenas ganha força em paralelo ao reconhecimento de seus direitos em esfera constitucional.

Há um esforço de agentes públicos que compõem o governo federal brasileiro no sentido de incorporar uma agenda no campo da educação que permita constituir um campo ético de sensibilidade e percepção aberto aos diferentes olhares que compõem a sociedade nacional. Em paralelo ocorreu um processo de concretização, num plano formal, de uma educação voltada aos projetos societários dos povos indígenas, seguindo seus próprios parâmetros lingüísticos, culturais e suas formas de transmissão, e que reconhecem os territórios como base do ordenamento administrativo das políticas públicas de educação escolar indígena.

\section{A educação superior para indígenas no Brasil}

Um olhar panorâmico sobre o processo de ingresso e formação de estudantes indígenas no ensino superior na América Latina remete, em uma escala temporal ampliada, ao marco histórico das ações do governo Cárdenas no México, na década de 1950, ao processo revolucionário e reivindicatório de justiça social da Colômbia, ocorrido na mesma época, com possíveis paralelos alargáveis para outros países.

Especificamente no Brasil a narrativa sobre a atenção indígena ao ingresso nas universidades possui diversas variantes, todas remontam ao final da década de 1970 como um ponto de partida.

A imagem deste ponto de partida é bem traduzida no depoimento do intelectual indígena Marcos Terena (2013: 09), reproduzido a seguir:

No ano de 1977, chegou a Brasília um grupo de quatro jovens indígenas em busca de uma bolsa de estudo para se prepararem por meio da educação ocidental e com o apoio do governo federal, a ingressarem no ensino superior. Em 1981, esse 
grupo já era de 15 jovens de sete povos, conhecidos como União das Nações Indígenas. Mas nesse mesmo ano, a FUNAI recebeu uma orientação "secreta" de um general chamado Golbery do Couto e Silva, mentor do governo militar, determinando a imediata expulsão de Brasília daquele grupo de jovens indígenas. O argumento: 'Brasília era uma cidade atípica para Índios' - 'Não podemos criar cobras para nos picar'. Ali e naqueles momentos, surgiu uma consciência indígena, primeiro sobre seu próprio valor como povo, e povo discriminado, e ao mesmo tempo, o renascer da indignação indígena diante de todo um processo de colonização que sempre os colocou como 'relativamente incapazes' e tratados de forma paternalista ou assistencialista, incluso o direito de decidir por eles. O sistema governamental não previu esse tipo de escolaridade indígena que conjuga novos conhecimentos e conscientização.

Paulatinamente, vai ganhando corpo o número de estudantes indígenas a ingressar nas universidades brasileiras, inicialmente nas instituições privadas e comunitárias, cujos estudos eram propiciados por agências de fomento internacionais de caráter filantrópico e religioso, as quais direcionavam recursos para o pagamento de bolsas de estudos (Rosa e Freitas, 2003).

De acordo com Mariana Paladino (2013), esta situação persiste até o final da década de 1990, sofrendo uma inflexão nos anos 2000 e nas palavras da autora:

\begin{abstract}
O acesso da população indígena à educação superior foi uma questão praticamente ausente das agendas governamentais e não governamentais até finais da década de 1990. Embora houvesse indígenas graduados - muitos deles lideranças destacadas no movimento indígena -, não havia uma reflexão sobre as possibilidades de a formação superior contribuir na aquisição de ferramentas para uma atuação mais efetiva dos próprios indígenas em projetos e ações de interesse para as suas comunidades. Por outro lado, ainda era pouco problematizada a desigualdade educativa no acesso dessas populações à educação superior como um todo, sendo que parecia mais urgente resolver os baixos índices de acesso à educação básica. (...) no ano de 2003, quando ainda eram poucas as universidades públicas com ações afirmativas, a FUNAl estimava que tivesse aproximadamente 1.300 indígenas na educação superior universitária, dos quais entre $60 \%$ e $70 \%$ estavam em instituições de ensino superior privadas (Paladino, 2013: 99).
\end{abstract}

Tal mudança no cenário brasileiro, no que se refere a políticas governamentais de educação superior para indígenas, está correlacionada, principalmente, com a Conferência Internacional contra o Racismo, a Xenofobia e a Intolerância Correlata, realizada em 2001, em Durban, na África do Sul. No entanto, a participação brasileira nesta Conferência não resultou em um processo automático de adoção de políticas de ação afirmativa nas diferentes áreas da vida pública no país. O governo federal da época, por exemplo, preferiu adotar medidas de incentivo à pré-vestibulares gratuitos que tinham por público preferencial estudantes negros, indígenas e moradores das periferias dos grandes centros urbanos.

De forma desarticulada, nos primeiros anos da década de 2000, iniciam as experiências em instituições públicas de ensino superior no país, cujos processos de democratização do acesso a componentes étnicos, raciais e sociais incluíram a reserva de vagas ou criação de vagas suplementares para estudantes indígenas. 
Este é o caso do sistema de universidades públicas estaduais do Paraná, que a partir de 2001 estabelecem um sistema local de vagas suplementares destinadas exclusivamente a estudantes pertencentes a comunidades indígenas do Paraná, através da implementação do Vestibular dos Povos Indígenas do Paraná. (Freitas e Harder, 2013).

No plano nacional, o início do primeiro governo do presidente Luis Inácio Lula da Silva (2002-2006) representou a criação de licenciaturas indígenas, as quais foram ofertadas em universidades federais em todo o país (Souza Lima e Barroso-Hoffmann, 2007). Em 2004, a Universidade de Brasília (UnB) estabeleceu um amplo programa de acesso e permanência voltado a estudantes negros e indígenas nos diferentes cursos de graduação, após um intenso debate em seu Conselho de Ensino, Pesquisa e Extensão. Esta universidade ampliou o espectro da política cuja matriz antecessora residia na Universidade Estadual do Rio de Janeiro (UERJ), porém com foco específico para estudantes negros.

A resolução aprovada na UnB, de certa forma, condensava experiências locais já existentes e se tornou paradigmática para um conjunto de outras universidades federais brasileiras, as quais passaram a incorporar estudantes negros e indígenas em seus quadros institucionais. Prova da capilarização da presença indígena nas universidades, em 2010 foi publicado o Edital 09/2010 do Programa de Educação Tutorial (PET) do Ministério da Educação expressando, no plano governamental, o reconhecimento da presença indígena nas universidades, ao prever a institucionalização e destinar recursos orçamentários para a criação de Grupos de Educação Tutorial voltados exclusivamente à formação de intelectuais indígenas em elevado padrão de excelência (Freitas, 2015).

O debate travado no interior da UnB e exposto nas atas públicas das reuniões dos conselhos universitários expressa a tensão vivida em uma instituição que foi precursora no Brasil de numa série de dispositivos normativos, retrato de um novo momento mundial no reconhecimento, implementação e efetivação de direitos humanos.

O debate na UnB revela que o movimento social negro estava fortemente organizado na afirmação e reivindicação de uma nova geração de direitos à educação, o que na dimensão indígena ainda se encontrava de forma difusa e dissolvida. Tal fato não significa que essa pauta fosse menos importante no âmbito das agendas indígenas, mas sim demonstra que o processo de representação indígena obedece a dinâmicas sociopolíticas diferenciadas, cujas agências, naquele momento, não acessaram o diálogo com a universidade.

\section{O processo administrativo de Ações Afirmativas na UnB e a ADPF n.186}

No ano de 2004, o Conselho de Ensino, Pesquisa e Extensão da UnB aprovou uma resolução que instituiu seu Plano de Metas para Integração Social, Étnica e Racial, com a previsão de:

1. Disponibilizar durante 10 anos $20 \%$ das vagas do Vestibular para estudantes negros em todos os cursos oferecidos pela universidade 2. Disponibilizar por um período de 10 anos, um pequeno número de vagas para índios de todos os Estados brasileiros (...); 3. Alocar bolsas para negros e indígenas em situação de carência, 
segundo critérios usados pela Secretaria de Assistência da UnB (...); 4. Propiciar moradia para estudantes indígenas e conceder preferência nos critérios de moradia para estudantes negros carentes (...). (STF, 2012: 03).

Tais dispositivos foram questionados pelo Partido Democratas (DEM) no Supremo Tribunal Federal, por meio de uma ação judicial denominada Arguição de Descumprimento de Preceito Fundamental (ADPF) n. 186, interposta em 2004, através de petição inicial composta por um volume com mais de 600 páginas.

A ADPF consta no texto constitucional dentre os mecanismos de controle da constitucionalidade. Este dispositivo da jurisdição constitucional está previsto no parágrafo único do artigo 102 da Constituição Federal de 1988, o qual também prevê que ao Supremo Tribunal Federal (STF) cumpre a "guarda da Constituição", considerada como "expressão de valores sociais e políticos" da nação.

A inspiração do sistema brasileiro está nas instituições da democracia norteamericana, com adaptações locais. O STF é composto por 11 Ministros, nomeados pelo Presidente da República, depois de aprovada a escolha pelo Senado Federal, dentre cidadãos brasileiros natos com mais de 35 e menos de 65 anos de idade, de "notável saber jurídico" e "reputação ilibada". As decisões da corte constitucional são consolidadas por meio de Acórdãos, os quais expressam a interpretação constitucional que deverá servir de matriz orientadora para todo o sistema jurídico brasileiro, bem como para a formulação de políticas públicas e tomadas de decisão da administração pública.

No caso especial da ADPF n. 186, movida pelo DEM (Partido Democratas), a argumentação concentra-se na interpretação de que a resolução da UnB ofende diversos artigos da Constituição Federal e de que os princípios étnico-raciais que fundamentam as ações afirmativas instituídas em 2004 na UnB estavam equivocados. Além disso, na ADPF n. 186 argumenta-se que a "discriminação supostamente existente no Brasil é uma questão social e não racial” (STF, 2012: 03).

De forma complementar, quanto ao mérito, a petição inicial registra que:

a) não se discute na ADPF, sobre a constitucionalidade de ações afirmativas, como gênero e como política necessária para inclusão de minorias;

b) não se discute acerca do reconhecimento de que o Brasil adota o modelo de Estado Social;

c) não se discute sobre a existência de racismo, de preconceito e de discriminação na sociedade brasileira. (STF, 2012: 04)

Durante o período de quase uma década em que esta ação judicial tramitou no Supremo Tribunal Federal, a execução das políticas de ação afirmativa pelas instituições de ensino superior aguardou o posicionamento oficial da Corte Constitucional. Paralelamente, o Congresso Nacional retardou a aprovação de um projeto de lei que regulamentava a temática e havia sido protocolado já em 2002.

Essa conjuntura resultou em um ambiente de liberdade e autonomia para as universidades no que se refere à instituição e regulamentação de políticas de ação afirmativa em todo o país. Não obstante, estabeleceu-se um olhar atento para a tramitação da ADPF n. 186 durante este longo período, por se reconhecer que o julgamento apontaria uma orientação segura para um processo de efetivação de uma 
nova geração de direitos fundados na perspectiva de igualdade material e busca de equidade social e oportunidades, ou ao contrário, reafirmaria o princípio universalista abstrato calcado na idéia de igualdade formal.

A ADPF n. 186 transformou-se, desse modo, em uma grande arena política em que se travou o debate com as diferentes posições sobre o assunto. Mais de uma dezena de instituições se inscreveu e solicitou o ingresso na ação judicial na qualidade de amicus curiae. Entre estas instituições se encontravam: a Defensoria Pública da União, o Instituto de Advocacia Racial e Ambiental, a Sociedade Afro-Brasileira de Desenvolvimento Sócio Cultural, a Fundação Nacional do Índio (FUNAI), o Conectas Direitos Humanos, a ONG Criola, a Fundação Cultural Palmares, o Conselho Federal da Ordem dos Advogados do Brasil (OAB), entre outras.

Somente em abril de 2012, em uma sessão pública, o Supremo Tribunal Federal se manifestou sobre a constitucionalidade das políticas de ação afirmativa em curso nas universidades brasileiras. O Ministro escolhido para relatar o processo foi Ricardo Lewandowski, o qual em 233 páginas consolidou o Acórdão sobre a temática, com o posicionamento unânime dos demais Ministros, acompanhando sua manifestação.

\section{Um olhar preliminar sobre o Acórdão da ADPF n. 186}

A análise do caso jurídico em questão envolveu um olhar atento ao sentido mais profundo do debate democrático expresso nos contraditórios que permearam a arena em torno da ADPF n. 186.

Antes de consolidar seu posicionamento, o STF promoveu uma audiência pública, ocorrida entre os dias 03, 04 e 05 de março de 2010, nas dependências da própria Corte Constitucional, em Brasília. Antecederam a realização da audiência inúmeras manifestações nos principais jornais e revistas de circulação nacional, com posicionamentos contrários e favoráveis às políticas de ação afirmativa. Diversos livros foram lançados durante o período como forma de reverberação dos debates que ocorriam no interior das universidades, instituições de representação profissional, movimentos sociais e centrais sindicais.

Os argumentos manifestados ao longo dos três dias de debate foram sintetizados e compõem um extenso panorama dos posicionamentos que antecede no Acórdão o voto do relator. Dentre as manifestações, figuram discursos de natureza antropológica, que polarizam as duas principais vertentes postas em debate nesta arena.

A antropóloga e professora do Departamento de Antropologia Cultural do Instituto de Filosofia e Ciências Sociais da Universidade Federal do Rio de Janeiro (UFRJ), Yvonne Maggie, não compareceu à Audiência Pública, "em decorrência de problemas de saúde". Entretanto, sua manifestação foi lida, por meio de uma carta e, em síntese afirmou que:

Setores do governo e certas organizações não governamentais, na busca de atalhos para a justiça social, querem impor ao Brasil políticas já experimentadas em outras partes do mundo, as quais trouxeram mais dor do que alívio. Acrescentou que leis raciais não tem o condão de combater as desigualdades, mas apenas estimulam a ideia de que as pessoas são desiguais e possuem direitos distintos conforme a raça (STF, 2012: 22). 
No mesmo sentido, a antropóloga, cientista política e docente na Faculdade de Filosofia, Letras e Ciências Humanas da Universidade de São Paulo (USP), Eunice Ribeiro Durham, também não compareceu à Audiência Pública, mas teve sua manifestação lida pela procuradora jurídica do DEM e autora da petição inicial da ADPF n. 186, Dra. Roberta Fragoso Menezes Kaufmann. De acordo com o texto que enviou:

(...) a adoção de cotas nas universidades apresenta vários aspectos negativos, a
exemplo da avaliação e seleção de estudantes não por mérito, mas por questões que
não influenciam o seu desempenho, como a cor da pele, tipo de cabelo, feições
faciais e origem étnica (...) o vestibular é uma forma de neutralizar a manifestação de
discriminações, visto que alunos de qualquer raça, renda, sexo são reprovados ou
aprovados exclusivamente em função de seu desempenho (STF, 2012: 22-23).

Durante a audiência pública, o DEM (Partido Democratas), que ajuizou a ADPF, através de sua advogada Roberta Fragoso Menezes Kaufmann, reiterou seu posicionamento pela inconstitucionalidade do sistema de cotas nas universidades públicas. É interessante notar que a representante jurídica do DEM ponderou em sua manifestação que a ação judicial "apenas questiona as cotas para negros nas universidades, mas que, em nenhum momento, se insurge contra as políticas de inclusão dos indígenas. Alegou, mais, que, por meio desta ação, busca 'identificar o que, em cada sociedade, deva ser considerada minoria apta a proteção estatal'. (STF, 2012: 19, grifos nossos).

Esta manifestação introduz uma ambiguidade, se cotejada com os objetivos da petição inicial. Não há clareza sobre a abrangência das ações afirmativas que se vêem questionadas pela ADPF. Aparentemente a argumentação contrária se restringe ao componente racial negro e, em especial, ao suposto poder conferido ao Estado para "definir quem é negro e quem não é" (STF, 2012: 05).

Na posição contrária, a antropóloga e professora Denise Jardim, representando a Universidade Federal do Rio Grande do Sul (UFRGS) correlacionou as ações afirmativas às "políticas públicas de promoção à cidadania por sinalizarem direitos constitucionais da coletividade que foram relegados às margens da dignidade humana". (STF, 2012: 20).

Nesta mesma direção, a Vice-Procuradora Geral da República, Deborah Duprat, representando o Ministério Público Federal (MPF), afirmou que: "o direito, rigorosamente, nunca foi alheio às diferenças. Pelo contrário, tratou delas cuidadosamente." Disse, ainda, que a Constituição de 1988, nos arts. 215 e 216, reconhece e protege, expressamente, o caráter plural da sociedade brasileira, recuperando o espaço ontológico da diferença. Para a Vice-Procuradora Geral, "as cotas, antes de atentar contra o princípio da igualdade, elas realizam a igualdade material." (STF, 2012: 17).

O cerne do debate captado pelo relator e convertido na qualidade de fundamento jurídico do Acórdão, reside justamente no alargamento da concepção de igualdade como elemento fundamental para a definição do princípio de realização da justiça social presente no Estado Democrático de Direito. Avança ainda para a redefinição 
dos critérios para ingresso no ensino superior, não mais restritos à interpretação formal do artigo 208, inciso $V$ da Constituição federal, o qual estabelece que "(...) o acesso aos níveis mais elevados do ensino, da pesquisa e da criação artística será efetivado 'segundo a capacidade de cada um'. (STF, 2012: 13).

A hermenêutica proposta pelo STF para o tema aponta que:

(...) não raro a discussão que aqui se trava é reduzida à defesa de critérios objetivos de seleção - pretensamente isonômicos e imparciais -, desprezando-se completamente as distorções que eles podem acarretar quando aplicados sem os necessários temperamentos. (STF, 2012: 13).

O voto do relator reconhece que vivemos em uma sociedade marcada "por desigualdades interpessoais profundas" (STF, 2012: 15). Esta leitura material permite a seguinte indagação: o que define a capacidade para ingresso no ensino superior? A resposta, num plano do reconhecimento da diferença, exige considerar que "as aptidões dos candidatos devem ser aferidas de maneira a conjugar-se seu conhecimento técnico e sua criatividade intelectual ou artística com a capacidade potencial que ostentam para intervir nos problemas sociais" (STF. 2012: 17, grifos nossos).

Ou seja, procedimentos de seleção diferenciados para ingresso nas universidades poderiam, com base nesta posição hermenêutica, levar positivamente em consideração o conjunto de capacidades aportadas pelos povos indígenas através de suas epistemologias, tecnologias, criações artísticas, agências políticas, etc.

Em última instância, a manifestação expressa no Acórdão deixa claro que o fim último do Estado é a realização da justiça distributiva, oportunizando a realização de uma melhor qualidade de vida para a pluralidade de indivíduos e coletivos que compõem a sociedade brasileira. O processo de seleção para a universidade deve estar atento a este objetivo maior que não se restringe à mera classificação, inclusão ou exclusão dos candidatos.

Em síntese, a discriminação positiva por meio das políticas de ação afirmativa encontrou pleno respaldo jurídico e constitucional no Acórdão da ADPF n. 186. Entretanto, toda sua construção e arcabouço argumentativo estabelecem como centro de análise hegemônico o segmento social dos estudantes negros. Residualmente a presença indígena é referida no Acórdão.

\section{A presença indígena no Acórdão}

A leitura atenta do Acórdão da ADPF n. 186 permite elevar a categorias centrais de compreensão o reconhecimento e afirmação positiva da pluralidade étnica e racial brasileira, em especial no âmbito das políticas educacionais.

A efetivação do princípio da igualdade substancial como premissa da efetivação de uma vida democrática e da transposição de arcaicas e assimétricas estruturas de poder, as quais condicionam historicamente o acesso à universidade e a legitimação dos regimes de produção do conhecimento acadêmico, está no centro da decisão da Corte Constitucional. 
Não obstante, chama a atenção o tratamento apenas residual dado à questão indígena no âmbito do texto jurisprudencial. A primeira menção à dimensão indígena ocorre logo na terceira página do Acórdão, durante a exposição do relatório com os argumentos e requerimentos que integram a petição inicial.

Neste tópico consta que entre "as disposições contestadas", se encontra a abertura de vagas para índios e o dever de propiciar moradia aos mesmos. (STF, 2012: 03). Somente após 10 páginas, na apresentação das instituições habilitadas na qualidade de amicus curiae, a FUNAI esclarece que:

(...) o sistema de cotas da UnB alcança também os indígenas e que a Ação visa acabar com qualquer sistema de cotas e não somente a dos negros.

(...) Alegou, em acréscimos, que no Brasil não há necessidade de empregar-se o critério de ancestralidade para definir quem é negro ou índio, tampouco utilizar exames genéticos, eis que aqui "o preconceito é de marca e não de origem". (STF, 2012: 13-14).

Na página 19, a advogada do DEM (Partido Democratas), Roberta Fragozo Menezes Kauffmann, retira o foco da ação sobre a dimensão indígena, mesmo que o prosseguimento da mesma impacte diretamente a prática administrativa então em curso nas universidades federais, em cujos quadros institucionais uma geração de indígenas já havia se formado e tantos outros ingressado no âmbito da mesma política de ação afirmativa.

Paradoxalmente, Kabengele Munanga, representando o Centro de Estudos Africanos da USP, expressa que "uma política de cotas para negros e indígenas não é para terem direito às migalhas, mas sim para terem acesso ao topo em todos os setores de responsabilidade e de comando na vida nacional em que esses dois segmentos não são devidamente representados" (STF, 2012: 24). A ausência de lideranças também do movimento indígena é de certa forma equalizada pelo posicionamento solidário do movimento negro.

Essa solidariedade é adensada na manifestação da jurista Flávia Piovezan, que lembra "expressamente, a importância das comunidades indígenas e afro-brasileiras na formação da cultura nacional" (STF, 2012: 25-26), nos termos dos artigos 215 e 216 da Constituição Federal brasileira.

Por fim, a UnB, após a audiência pública, aportou sua manifestação sobre o mérito da ação afirmando que "a ausência, no serviço publico de negros e índios em profissões tais como médicos, juízes, procuradores, psicólogos, diplomatas, para citar exemplos, enfraquece a capacidade de o Estado lidar não apenas com a sua própria diversidade étnica interna, mas com a mundial diferença das populações" (STF, 2012: 34). Porém, a menção à dimensão indígena se restringe a esta passagem específica, e os demais exemplos mencionados no Acórdão dizem respeito somente a população negra.

No voto em si, embora o critério étnico-racial esteja em análise como um todo, o foco na perspectiva dos estudantes negros e da temática racial não somente são hegemônicos como compõem a totalidade. A presença indígena no voto é mencionada tão somente um pouco antes da parte dispositiva que julga improcedente a ADPF $n$. 186 e discorre sobre a proporcionalidade entre meios e fins na reserva de "um 
pequeno número" de vagas para "índios de todos os estados brasileiros", pelo prazo de 10 anos, como uma providência adequada. (STF, 2012: 46).

Nas páginas seguintes do Acórdão encontramos as manifestações de todos os demais Ministros do Supremo Tribunal Federal e, invariavelmente, a presença indígena sequer é mencionada.

A fundamentação do voto do relator é enaltecida pelos demais membros da Corte Constitucional e considerada uma síntese teórica abrangente e profunda sobre a temática. Observe-se que o Ministro Joaquim Barbosa ressalta a qualidade do voto e de que em sua origem acadêmica defendeu tese sobre o assunto a qual foi publicada posteriormente e constitui referência no paralelo entre a afirmação dos direitos à diferença nos Estados Unidos e Brasil, especificamente na implementação das políticas de ação afirmativa por universidades.

\section{Considerações finais}

No presente artigo lançamos um olhar preliminar sobre o texto do Acórdão da ADPF n. 186, buscando destacar seus fundamentos e tecer uma leitura atenta à presença das alteridades indígenas neste documento, bem como aos discursos antropológicos que se fizeram presentes na arena por ele instaurada na Corte Constitucional brasileira.

A extensão e densidade do texto jurídico requerem novas análises. É possível abstrair, não obstante, que embora a dimensão étnico-racial das políticas de ação afirmativa seja analisada como um todo, sobressai o esmero e a prevalência da dimensão raça enquanto eixo de análise, em detrimento da dimensão étnica, a qual surge residualmente e em caráter secundário no conjunto do Acórdão.

Não há como deixar de observar que ao longo de quase uma década os estudantes indígenas, e todos os demais agentes envolvidos com o ensino superior para indígenas no Brasil, aguardavam um posicionamento da Corte Constitucional para o avanço de suas ações.

Durante as sessões de julgamento no STF, caravanas de estudantes indígenas e o próprio movimento social indígena acompanharam atentamente os desdobramentos da leitura do Acórdão e seus debates.

A quase invisibilidade da alteridade indígena a compor o leque de opções que resultem em uma maior pluralidade social e cultural nas universidades brasileiras, deve ser interpretada em conjunto com as demais decisões do Supremo Tribunal Federal que envolvem os direitos indígenas.

Essas decisões revelam um descompasso com a ética do Bem Viver, pautada pela Corte de Direitos Humanos da OEA, a qual vem sendo cotejada nos planos constitucionais de outros países latino-americanos e reivindicada pelos povos indígenas no Brasil.

No caso brasileiro, o antecedente julgado com relação à Raposa Serra do Sol, por exemplo, terra indígena reconhecida em sua integralidade como direito territorial dos povos indígenas, revela o ideal de integração nacional como premissa ontológica dos posicionamentos do STF, se realizado o cotejo com as condicionantes impostas à demarcação. 
Paradoxalmente, a superficialidade do tratamento dado à dimensão indígena no Acórdão da ADPF n. 186, em que pese a farta experiência acumulada pelas universidades brasileiras na temática, indica o longo caminho a ser percorrido no plano de uma "ecologia dos reconhecimentos" pelos povos indígenas no Brasil, para além de uma "sociologia das ausências" (Santos, 2008: 111).

\section{Bibliografía}

Cunha, Manuela Carneiro da (1987) Os direitos dos índios: textos e documentos. São Paulo: Brasiliense.

Dworkin, Ronald (2011) A virtude soberana: a teoria e a prática da igualdade. 2.ed. São Paulo: Martins Fontes.

Freitas, Ana Elisa de Castro, Augusto Ope da Silva (2014) Pensamento e ação de um wãnh-wuntàr/guerreiro-dançador. Espaço Ameríndio. Vol. 8. N. 02. Porto Alegre: PPGAS/UFRGS, jul/dez. pp. 303-319. Disponível em: http://seer.ufrgs.br/index.php/EspacoAmerindio/article/view/51829/32625

. (org.) (2015) Intelectuais indígenas e a construção da universidade pluriétnica no Brasil. Série Abrindo Trilhas. Rio de Janeiro: Editora E-papers.

. e Harder, Eduardo (2013) Da política de Estado ao estado da política: panorama de uma década de ensino superior indígena no Paraná. In: Bergamaschi, Maria Aparecida; Nabarro, Edilson; Benites, Andréa. Estudantes indígenas no ensino superior: uma abordagem a partir da experiência na UFRGS. Porto Alegre; Editora da UFRGS, pp. 169-182.

Garavito, César Rodríguez (Coord.) (2011) El derecho en América Latina: un mapa para el pensamiento jurídico del siglo XXI. Buenos Aires: Siglo Veintiuno Editores.

Gargarella, Roberto (2015) La sala de máquinas de la Constitución: dos siglos de constitucionalismo en America Latina (1810-2010). Buenos Aires: Katz Editores.

Paladino, Mariana (2013) Um mapeamento das ações afirmativas voltadas aos povos indígenas no ensino superior. In: Bergamaschi, Maria Aparecida; Nabarro, Edilson; Benites, Andréa. Estudantes indígenas no ensino superior: uma abordagem a partir da experiência na UFRGS. Porto Alegre; Editora da UFRGS, pp. 99-112.

Piovesan, Flávia (1996) Direitos humanos e o direito constitucional internacional. São Paulo: Max Limonad.

Santos, Boaventura de Sousa (2008) A gramática do tempo: para uma nova cultura política. 2.ed. São Paulo: Cortez.

Souza Lima, Antonio Carlos (Coord.) (2012) Antropologia e direito: temas antropológicos para estudos jurídicos. Rio de Janeiro/Brasília: Contracapa/Laced/ABA.

; Barroso-Hoffmann, Maria (Org.) (2007) Desafios para a educação superior para os povos indígenas no Brasil: políticas públicas de ação afirmativa e direitos culturais diferenciados. Rio de Janeiro: Museu Nacional/Laced/Trilhas de Conhecimentos.

Terena, Marcos (2013) O estudante indígena no ensino superior. In: Bergamaschi, Maria Aparecida; Nabarro, Edilson; Benites, Andréa. Estudantes indígenas no ensino superior: uma abordagem a partir da experiência na UFRGS. Porto Alegre; Editora da UFRGS, pp. 09-14.

Zaffaroni, Eugenio Raúl (2013) La Pachamama y el humano. Buenos Aires: Colihue/Ediciones Madres de Plaza de Mayo. 
Yrigoyen Fajardo, Raquel (Org.) (2010) Pueblos indígenas. Constituciones y reformas políticas en América Latina. Lima: Instituto de Estudos SocioeconómicosINESC. 